This is a self-archived version of an original article. This version may differ from the original in pagination and typographic details.

Author(s): Portegijs, Erja; Rantanen, Taina

Title: Life-space mobility and active ageing

Year: 2019

Version: Accepted version (Final draft)

Copyright: (c) The Authors, 2019.

Rights: In Copyright

Rights url: http://rightsstatements.org/page/InC/1.0/?language=en

Please cite the original version:

Portegijs, E., \& Rantanen, T. (2019). Life-space mobility and active ageing. In A. P. Lane (Ed.), Urban Environments for Healthy Ageing : A Global Perspective (pp. 89-102). Routledge.

Routledge Advances in Sociology, 267. https://doi.org/10.4324/9780429243097-6 


\section{Life-space mobility and active ageing}

\section{Erja Portegijs}

http://orcid.org/0000-0002-5205-9616

Dr. Erja Portegijs, Senior Researcher, leads a research line studying person-environment interactions in mobility, physical activity and active aging. She has over 60 peer-reviewed publications in the fields of gerontology, sport sciences and public health.

\section{Taina Rantanen}

http://orcid.org/0000-0002-1604-1945

Dr. Taina Rantanen, professor of gerontology and public health, is an internationally recognized and awarded expert in aging research. Her research interests include mobility, life-course influences on aging and promoting active aging. She is currently the principle investigator of a large interdisciplinary study on active aging, which is funded by an advanced grant from the European Research Council.

This chapter highlights the research on the concepts of life-space mobility and active aging. With age, the life-space of older people becomes more restricted and they spend more and more time in or around their home, a situation that increases the risk of social isolation, physical inactivity and poor quality of life. Optimal mobility is the result of a good balance between the environmental demands and affordances, on the one hand, and the personal resources and capacity of the individual, on the other hand. Furthermore, this chapter describes a new tool developed by our team to assess active aging at the level of the individual, rather than at the 
policy level. The final section discusses intervention strategies that improved opportunities for participation and well-being of older people. 
9. Life-space mobility and active ageing

Erja Portegijs, Taina Rantanen

Gerontology Research Center, Faculty of Sport and Health Sciences, University of Jyväskylä

Author Note

The authors and their research projects were financially supported by the Academy of

Finland (e.g. grant number 255403 and 310526), the Finnish Ministry of Education and Culture, and the Finnish Slot Machine Association. Currently, funding is received from the European Research Council (ERC Advanced grant 693045 to TR).

Correspondence address of the authors:

Gerontology Research Center (GEREC)

Faculty of Sport and Health Sciences

P.O. Box 35 (viv 149)

40014 University of Jyväskylä, FINLAND 


\section{Life-space mobility and active ageing}

Functioning in old age depends on early life influences, individual characteristics and environmental influences. Typically, the functioning of most body systems is optimal in early adulthood and inevitably declines with increasing age. However, the maximal functional capacity achieved and the rate of decline determine the threshold beyond which functioning progresses into disabilities in daily activities, such as walking. Early life influences, such as nutritional status or level of physical activity, affect the reserve capacity to maintain functioning into old age (Kulmala et al., 2016; Stenholm et al., 2012; von Bonsdorff et al., 2011). Current influences on functioning, such as acute and chronic medical conditions, affect the general rate of decline. Many environmental factors including those in the physical neighbourhood environment can modify the threshold beyond which disability occurs (Lawton \& Nahemow, 1973).

Mobility refers to an individual's ability to move a body position or to move oneself from one place to another either with muscle activity or by using a vehicle. Mobility is an essential building block of independent functioning and an important pre-requisite for fully engaging in meaningful activities (Satariano et al., 2012). Life-space mobility refers to the spatial area where an individual purposefully moves through (room, yard, neighbourhood, town and beyond) and reflects an individual's access to community amenities and opportunities to take part in different life situations. Life-space mobility, which includes both active and motorized movement through larger areas, can thus be viewed as a measure of participation (Baker, Bodner, \& Allman, 2003). The health challenges and functional disabilities older adults face make them vulnerable to environmental barriers. As a result, they may spend more and more time in their homes or in the vicinity, eventually becoming practically home confined. This increases the risk of social 
isolation, physical inactivity and poor quality of life while also increasing the probability for becoming dependent on external help.

The final section of this chapter covers active aging. The World Health Organisation (WHO) defines the policy goal of active ageing as the process of optimising opportunities for health and participation in society for all people in line with their needs, goals and capacities as they age (World Health Organization, 2002a). Active ageing when defined from an individual's stand point, rather than from a political context, takes into account life goals and thus is potentially an important aspect of an older individual's wellbeing (Rantanen et al., 2018). According to our definition, active ageing of individuals is the striving for elements of wellbeing through activities as per an individual's goals, abilities and opportunities. The diversity of active ageing may stem from societal, environmental and individual differences.

In the final section of this chapter we will consider the need to develop interventions to improve older people's opportunities for participation. We talk about interventions to prevent mobility decline as well as its consequences (e.g. social isolation) targeting the individual or the external environment.

\section{Mobility.}

Mobility of older people is commonly studied as walking or other active movements. Yet, mobility activities span everything from muscle activity to using a motorized vehicle for transportation. Mobility function is highly dependent on sensory, musculoskeletal and cognitive functioning, regardless of whether one uses a vehicle or not (Poranen-Clark, von Bonsdorff, Rantakokko, Portegijs, Eronen, Kauppinen et al., 2018; Sakari et al., 2010). For example, for walking, sensory information, such as vision and balance, muscle function and coordination of movements are crucial. Considering that walking occurs in an environment, an individual also 
needs to be able to make sense of the environment and thus cognitive processes are involved. Using a motorized vehicle such as a car may be less demanding in terms of muscle function, but more demanding in terms of reliance on rapid interpretation of sensory information and cognitive processes. Consequently, age-related declines in sensory, physical and cognitive functioning pose increasing challenges to mobility of an older adult.

\section{Life-space mobility and the LISPE study.}

Due to health challenges with increasing age, or age-related functional declines, people spend more and more time in their home or its vicinity and eventually people may become practically home confined. Consequently, the design of home and the immediate environment may directly affect an individual's possibilities to leave the home and move through areas further away from the home.

Life-space is the spatial area through which one purposefully moves. The life-space of an individual may be limited to the bedroom, for example in the case of a bedridden patient, or it may span other rooms in the home, the yard, the neighbourhood, and the town and, at its largest, also beyond the home town. In addition to the spatial area, the frequency of movement and the need for assistance are relevant when considering the overall mobility of an individual and are included in the summary score of life-space mobility (Baker et al., 2003). Thus life-space mobility reflects an individual's access to community amenities and opportunities to take part in different life situations. The smaller the area one moves through, the less frequent one moves, or the more assistance one needs, the fewer opportunities for meaningful activities are available to the individual.

In a large Finnish research project 'Life-space mobility in old age' (LISPE) 848 older adults aged 75-90 years living independently in Jyväskylä and Muurame municipalities in 
Central Finland were studied (Rantanen et al., 2012) and re-assessed annually for two years (Rantakokko et al. 2016a). Life-space mobility was assessed with the Finnish translation of the University of Alabama at Birmingham Life-Space Assessment, which has been shown valid and reliable (Portegijs, Iwarsson, Rantakokko, Viljanen, \& Rantanen, 2014). The questionnaire asks about the previous four weeks and comprises 15 items. For each life-space level (home, yard, neighbourhood, town, beyond) the frequency of movement (daily, 4-6 times a week, 1-3 times a week, less often) and the need for assistance (personal assistance, assistive device, no assistance needed) was asked. From this, a sum score was computed ranging from 0-120. A score of 0 would indicate that the individual is completely bedridden and fully dependent on other people. A score of 120 would indicate that the individual moves daily to an area beyond their home town without using any walking aids or personal assistance.

\section{Consequences of life-space mobility}

Life-space mobility restriction may be an early sign of declining function and increasing vulnerability to disability in old age. In the LISPE, restricted life-space mobility, as indicated by a score of 52.3 points or lower on the Life-Space Assessment questionnaire, predicted the development of new difficulty and new disability in activities of daily living (ADL) over the two-year follow-up (Portegijs, Rantakokko, Viljanen, Sipila, \& Rantanen, 2016). Such a score likely means that the individual rarely moves beyond their own neighbourhood. In addition, large declines, of more than 11.7 points, in life-space mobility over the two year period were associated with development of new ADL difficulty and disability. Such a change may, for example, occur when an older individual stops driving or starts to experience difficulties in walking and therefore no longer goes beyond their neighbourhood on a weekly basis. Depending on the use of walking aids, such a change in experience and circumstance would cause a decline 
of 10-16 points in the life-space mobility score. Many older people wish to age in their own home. In addition, there is considerable pressure from the society on older people to age independently in their own home. However, this is only possible if functional declines are recognized early on in the trajectory towards disability, as early recognition of impairments may open up possibilities for less intense but effective interventions enabling the modification of the downward trajectory.

Restricted life-space mobility is associated with poorer quality of life in general and in all subdomains (Rantakokko, Portegijs, Viljanen, Iwarsson, \& Rantanen, 2013). Quality of life is a multidimensional concept which includes physical, mental social and environmental aspects. Marked declines, that is, more than 10 points, in life-space mobility over a period of two years were associated with reductions in quality of life among the LISPE participants (Rantakokko et al., 2016a). The importance of having greater life-space mobility for an individual is furthermore illustrated by the finding that participants with the lowest life-space mobility rarely reported high quality of life.

\section{Life-space mobility determinants.}

The Short Physical Performance Battery (SPPB) comprises a balance, and a walking and a repeated chair-rise test, and is a generic measure of lower extremity performance. Higher performance in the SPPB is associated with greater life-space mobility for older people (Portegijs, Rantakokko, Mikkola, Viljanen, \& Rantanen, 2014). Yet, greater life-space mobility is, in addition to physical factors, associated with a good sense of autonomy in outdoor mobility, a psychosocial factor. A good sense of autonomy reflects the feeling that one has control over decisions about when, where and how to leave home to participate in meaningful activities. The importance of physical and psychosocial factors seemed to be higher in older ages and for 
women, coinciding with a higher prevalence of functional impairments and adverse health conditions.

Executive functioning refers to higher-order cognitive abilities, which are required when planning and carrying out complex, goal-oriented behaviours. Lower executive function is associated with more restricted life-space mobility (Poranen-Clark et al., 2018) and predicts greater declines in life-space mobility in the LISPE sample over two years (Poranen-Clark, von Bonsdorff, Rantakokko, Portegijs, Eronen, Pynnonen et al., 2018). However, poorer physical performance and transportation difficulties explained the association between executive function and life-space mobility (Poranen-Clark et al., 2018).

Disparities in health and functioning have been associated with differences in socioeconomic status. Low socioeconomic status, assessed as educational attainment or occupation, has been associated with more restricted life-space mobility (Eronen et al., 2016). However, overweight, reduced cognition, and poorer physical performance often coincide with low socioeconomic status and restricted life-space mobility, thus potentially indicating an underlying mechanism.

Life-space mobility is the result of the person-environment fit, which means that the extent of life-space mobility depends on factors related to the individual as well as on environmental factors such as transportation options and characteristics of the physical neighbourhood environment. Driving a car is especially important for maintaining greater lifespace mobility, when compared to traveling as car passenger, using public transportation or other means, especially for older people with walking limitation (Viljanen, Mikkola, Rantakokko, Portegijs, \& Rantanen, 2016). For men, the association between driving and life space mobility is more pronounced than it is for women. Additionally, the LISPE study showed that a higher 
number of environmental barriers for outdoor mobility is associated with a more restricted lifespace mobility, while a higher number of environmental facilitators for outdoor mobility is associated with greater life-space mobility in older people (Rantakokko, Iwarsson, Portegijs, Viljanen, \& Rantanen, 2015).

\section{Optimal mobility.}

Mobility is optimal when one can go where one wants to go, when one wants to go, and how one chooses to go there (Satariano et al., 2012). Optimal mobility is the result of a good fit between the capacity of an individual and the demands of their environment (Iwarsson, Horstmann, Carlsson, Oswald, \& Wahl, 2009; Lawton \& Nahemow, 1973). Therefore, an older individual who faces reduced functional capacity due to health decline, for example, will be more vulnerable to environmental barriers. In the LISPE study, environmental barriers relating to home entrances and neighbourhoods have been associated with lower out-of-home mobility (Portegijs, Rantakokko, Viljanen, Rantanen, \& Iwarsson, 2017; Rantakokko et al., 2015) and, in the SCAMOB study, with declines in mobility function over a 3.5-year period (Rantakokko, Iwarsson, Manty, Leinonen, \& Rantanen, 2012; Rantakokko et al., 2016b). The 'Screening and Counselling for Physical Activity and Mobility' (SCAMOB) study comprised communitydwelling people, aged 75-81-years, living in the city centre of Jyväskylä, Finland, who were moderately physically active or sedentary and able to walk $500 \mathrm{~m}$ without help from another person. Only the control group participants were used for these prospective analyses of naturally occurring changes.

Environmental barriers such as slopes and stairs may pose a huge challenge to overcome for some people, while for well-functioning individuals the same environmental features may not encumber their outdoor mobility. Environmental barriers may also be related to social or 
financial factors such as carer obligations and financial constraints. These factors may also affect an individual's ability to move. Conversely, data from the SCAMOB show that when a person lives alone, they may be forced to go out and walk for errands, regardless of the presence of environmental barriers (Tsai et al., 2013). Importantly, features in the environment may also stimulate people to go outdoors and be physically active. In the SCAMOB, reporting attractive features in the environment, such as nature and beautiful outdoor areas, decreased the risk of developing walking difficulties over a 3.5-year follow-up (Eronen, von Bonsdorff, Rantakokko, \& Rantanen, 2014).

Older adults are a very heterogeneous group of individuals. It is important to differentiate between those who have relatively good mobility and those with (early) limitations, who are at a higher risk for further decline in function and more vulnerable to environmental barriers. In accordance with Baltes \& Baltes's (1990) model of selection, optimization and compensation, individuals seek to optimize their behaviour and adapt their strategies in order to minimize costs (e.g. excessive energy use). Consequently, compensatory strategies are used by individuals in order to sustain activity. For example, walking more slowly may enable larger distances to be covered without getting exhausted. The use of a walking device may enable an individual to continue walking independently even when facing balance problems. Compensatory strategies may also relate to the physical environment, for example, selecting a route with suitable places to sit on and rest may enable an individuals to cover larger distances than their physical capacity would otherwise allow.

When compensatory strategies no longer suffice, an individual will modify their behaviour by more carefully selecting activities, for example, walk shorter distances only, in order to maintain and optimize the energy balance. The LISPE has shown that using mobility 
modifications may be a positive adaptation by providing evidence that mobility modifications postpones the decline in life-space mobility (Rantakokko, Portegijs, Viljanen, Iwarsson, \& Rantanen, 2017) and makes people less vulnerable to environmental barriers (Rantakokko, Portegijs, Viljanen, Iwarsson, \& Rantanen, 2016).

Research suggests that a barrier-free environment is important for the out-of-home mobility of older people, especially among those with functional limitations. Yet, we have observed that people who do not move around in their neighbourhood independently, do not report environmental barriers due to lack of awareness. This is exemplified in secondary analyses of the ProMo study, which is a randomized controlled trial of multicomponent home-based rehabilitation of hip fracture patients living independently in the community in Central Finland (Portegijs et al., 2013). Before the hip fracture, most participants had been relatively active and well-functioning. The hip fracture compromised their mobility function and reduced their activity level. Shortly after the hip fracture, participants reported only few environmental barriers in their neighbourhood as their understanding of the environment was largely based on their prefracture experience. Over the course of the rehabilitation program when their outdoor mobility increased, they reported more perceived environmental barriers. The number of barriers perceived was thus not a reflection of the environment changing. It was a reflection of them now facing certain environmental features as barriers even though before the fracture they had not recognized these features as barriers.

Associations between facilitating factors in the environment and outdoor mobility may differ according to the presence of mobility limitations. Physical activity is an important component of outdoor mobility and life-space mobility. A satellite study of LISPE, including geographic information sources to assess the objective environment, showed that the presence of 
water and lakes within $500 \mathrm{~m}$ from the home was associated with higher physical activity levels among those with walking difficulties (Keskinen, Rantakokko, Suomi, Rantanen, \& Portegijs, 2018). For older people without walking difficulties, higher habitat diversity within natural areas located within $1000 \mathrm{~m}$ from the home was associated with higher physical activity levels. This suggests that older people view environmental features that suit their physical capacity as factors motivating them to go outdoors.

An objective indicator of the possibilities to walk to different destinations within an area is the walkability index (Frank, Andresen, \& Schmid, 2004). The walkability index is constructed from geographical information of land use mix, population density, and connectivity and may thus be useful for planning purposes. Evidence from the LISPE showed that when older individuals live in an area with a higher walkability index their physical activity level is more likely higher than that of those living in a less walkable environment (Portegijs, Keskinen, Tsai, Rantanen, \& Rantakokko, 2017). However, especially among those with physical limitations, these associations were rather weak. In contrast, reporting many environmental facilitators for outdoor mobility was associated with higher physical activity levels. Consequently a barrier-free home environment that also provides appropriate stimuli for out-of-home mobility is essential for outdoor mobility when facing functional limitations.

The perception of environmental barriers and facilitators for mobility reflects objective features of the environment, as well as the individual's capacity and the actual environment used by the individual. In addition, environmental facilitators may depend on individual preferences. As such, perceived environmental factors may be closely associated with the behaviour of an individual. For environmental planning purposes objective measures of the environment are commonly used. Yet research has shown that objective and subjective measures of the 
environment do not necessarily correlate well (Portegijs et al., 2017; Portegijs, Rantakokko, Viljanen, Rantanen, \& Iwarsson, 2017). Administrative units or circular buffers are commonly used as area descriptors to study objective features of the environment. When using objective measures of the environment it is not possible to account for the capacity or preferences of individuals or to know what environment the people actually use. However, the neighbourhood as defined by the individual or the environment used by the individual may be different, for example, biased towards a certain direction such as e.g. location of friends and family, favourite stores or events. Obtaining subjective information on perceptions of environmental barriers and facilitators is therefore essential when planning an environment that enables, and preferably facilitates, mobility for all.

\section{Daily life.}

Walking is the most common physical activity of older people. In the LISPE, people with higher step counts and longer time spent in at least moderate intensity physical activity also had higher life-space mobility (Tsai et al., 2015). They also maintained a higher life-space mobility over a two-year period (Tsai, Rantakokko, Rantanen et al., 2016). The LISPE showed that on those days when older people leave home, their step count approximately doubles compared to days when they stay indoors all day (Portegijs, Tsai, Rantanen, \& Rantakokko, 2015).

Furthermore, the step count further increases when the individual moves through their neighbourhood or town. Consequently, moving (more) frequently through greater life-space areas, regardless of vehicle use, may increase physical activity and provide health benefits in addition to opportunities to participate in meaningful activities. Considering that activities such as shopping correlate with higher step counts (Tsai, Rantakokko, Viljanen et al., 2016) and that short distances to services is one of the most frequently reported environmental facilitator by 
Finnish older people (Rantakokko et al., 2015), daily activities in which individuals leave their home play an important role in maintaining health and function.

\section{Active ageing.}

It is important to realize that all people, including older people, often act according to their personal goals in life (Saajanaho et al., 2015; Saajanaho et al., 2016). Personal goals are highly individualized states that people strive to achieve or avoid in the future (Freund, \& Riediger, 2006). The LISPE showed that individuals reporting a higher number of goals had greater life-space mobility and also maintained a greater life-space mobility over the two-year follow-up (Saajanaho et al., 2015; Saajanaho et al., 2016). In addition, reporting specific goals related to activities and maintaining functioning correlated with greater life-space mobility. In contrast, having no goals in life was associated with more constricted life-space mobility. Thus, using an approach that considers life goals should be beneficial in terms of promoting activity and well-being in old age.

Unfortunately, life goals and agency of older people have often been overlooked in ageing research. Sometimes researchers are guilty of rhetoric referring to older people as a uniform, less capable group of people, while also viewing them as a burden and an item of expenditure. It is quite common that researchers view older people as objects and these views may be reflected in how the media and the policymakers talk about ageing and may be counterproductive for promotion of wellbeing.

To counteract negative views about ageing, avoid ageism, and enhance a more comprehensive view about ageing, a perspective of positive gerontology emerged in the 1950's and expanded thereafter. Dr. Ethel Percy Andrus, a retired high school principal, founded the American Association of Retired Persons (AARP) in 1958 with a philosophy to promote 
productive ageing by encouraging older people to "To serve, not to be served" (AARP; https://www.aarp.org/about-aarp/company/info-2016/history.html).

Since then, positive terms such as productive ageing, successful ageing, healthy ageing and active ageing have been increasingly used by researchers and policymakers. The concept of active ageing stems from the work of Robert Havighurst who launched the activity theory (Havighurst, 1961). Activity theory posits that staying active in later life will lead to maintenance of wellbeing. World Health Organization (WHO) defined the policy goal of active ageing in 2002 as follows: "Active aging is the process of optimizing opportunities for health, participation and security in order to enhance quality of life as people age" (World Health Organization, 2002a). The same document also states "these policies and programmes should be based on the rights, needs, preferences and capacities of older people”. The WHO definition of active ageing is set as a goal for societies. The idea is to promote participation of older individuals in valued activities through legislation, adapting work life, social security schemes, environmental and urban planning, health services and civil society. At the societal level, Active Ageing Index ranks countries according to indicators such as participation of older people in the workforce or life-expectancy (Active ageing index; https://statswiki.unece.org/display/AA).

There is a distinction between active ageing policies and research on active ageing of individuals. Policies are actions of authorities, such as enforcing positive or negative sanctions (for example, tax cuts vs. fines, laws, regulations) meant to support or prevent specific actions among individuals or institutions. Policy represents the societal terms of reference for individual active ageing. To assess the active ageing of individuals, we need a description of active ageing that focuses on the individual. To this end, we have developed the following definition of active ageing: "The striving for elements of wellbeing through activities relating to a person's goals, 
functional capacities and opportunities" (Rantanen et al., 2018). This definition encompasses the four central sides in the active ageing of individuals: their goals (what they want to do), their functional capacity (what they are able to do), their autonomy (perceived opportunities to do the valued activities) and their activities (what they actually do). We hypothesize that active ageing maintains or promotes wellbeing. Our idea of the four essential sides of active ageing is in line with the framework of health behaviour changes put forward by Michie, van Stralen, and West (2011). In their 'behaviour system' three essential conditions underlying health behaviour are suggested: capability, opportunity, and motivation (COM-B). They identified these conditions in the context of health behaviour change interventions and policies, while our perspective is on activity and participation.

The assessment of intervention and policy effectiveness requires a valid method of measuring the outcome. Promoting active ageing is currently a widely accepted goal, however, no quantifiable method of assessment of active ageing of individual people has been available until recently. To this end, the Gerontology Research Center at University of Jyväskylä developed a method of assessing active ageing for use in research and practice. Our scale is entitled the University of Jyvaskyla Active Ageing Scale (UJACAS; Rantanen et al., 2018). The scale development was a multiphase process where we placed high value on theory, participant feedback and data analysis. First, an expert panel created a draft version of the assessment scale. The starting point for developing the scale items were the Activities and Participation categories of the International Classification of Functioning, Disabilities and Health (World Health Organization, 2002b) which provides a valid well conceptualised classification of essential life areas. As a result, the expert panel produced a 24-item draft questionnaire that was then tested in a pilot study among a convenience sample of 155 older people. The pilot study assessed the item 
properties, condensed the scale, and assessed its validity and reliability. The resulting condensed pilot scale with 15 items was exposed to two focus groups of older people consisting of four and five people to gain their input and views in the feedback study phase. The participant feedback on the scale led to the addition of two further items. The resulting final active ageing scale comprised 17 items. The final phase of the scale development was test-retest analysis to determine the stability and reliability over time of the final UJACAS (For more details of the scale development, see Rantanen et al., 2018). The psychometric scale properties were good and the scale assesses a unidimensional latent construct of active ageing.

\section{Promoting active ageing.}

What does promotion of active ageing entail? In addition to the policy actions directed towards an age-friendly society, we suggest that it entails promotion of older people's active agency in participation in valued activities in the context of their individual lives. This refers to actions taken by the older people themselves, their next of kin and friends, and professionals that may work with older people. This denotes taking a broader view on activity than performing specific activities. Activity limitations increase with age and declining functioning, and as a result activity will become difficult. However, participation is - in principle - possible for all regardless of their functional limitations. Compensatory strategies (e.g. assistance) to counteract physical limitations may prevent participation restriction even though the functional ability of an individual is low.

Active ageing takes diverse forms, as the goals and preferences of older people are diverse. In our earlier study, 'Volunteering, Access to Outdoor Activities and Wellbeing in Older People' (VOW), we assessed the unmet activity needs of older people with severe mobility limitations (Rantanen et al., 2015). Unmet activity need refers to an activity that the individual 
wanted to do but had no opportunity to do. The VOW participants were individuals aged 65 years or over living alone in the city of Jyväskylä, Finland, but having severe difficulties in accessing the outdoors independently. Almost $70 \%$ of these participants with severe mobility limitations reported unmet activity needs, suggesting that people wanted to take part in different activities but had no opportunity to do so. However, the most informative and noteworthy observation was that the unmet activity needs were highly individual. Some individuals reported that they would like to go to do art (e.g. singing in a choir, playing an instrument, painting), attend cultural events (e.g. concerts, theatre, movies, exhibitions), attend civic society activities or parish activities, do crafting, go to the market or a coffee shop, attend other social or club activities, or enjoy the outdoors. Consequently, a "one size fits all" intervention is not suitable for promoting active ageing. To promote active ageing, it may be helpful to target activities in line with the goals and interests of older people as a starting point of any intervention.

In the VOW intervention study, the idea was that volunteers assisted older adults with severe mobility limitations to various out-of-home activities based on their interests and needs (Rantanen et al., 2015). The volunteer, the participant and the project coordinator discussed together about the out-of-home activity interests of the participant, and made an activity plan for the intervention period. The interventions included activities such as going for walks, visiting places of interest (e.g., the harbour, parks, or art and craft exhibitions) or cultural events, or taking care of daily errands. The volunteer and the participant met once a week for a 3-month period to do the planned activities. In a sense, the intervention goal was to increase life-space mobility by providing assistance to one meaningful out-of-home activity per week. The study results suggested that the individualized active ageing intervention promoted the physical dimension of quality of life for old people with severe mobility limitations living in the 
community (for a more detailed description, see Rantanen et al., 2015). A likely explanation for this finding was the improved self-efficacy of the individual that resulted from resuming out-ofhome activities that they had not been doing for some time. Self-efficacy refers to one's belief in one's own ability to complete tasks and reach goals (Bandura, 1977). Having positive experiences about actually going outdoors may restore the perceived functional abilities of individuals. The VOW study showed that going outdoors with the help of the volunteer supported identifying, facing and solving physical and mental barriers for outdoor activities thus making the outdoors more accessible (Rantanen et al., 2015). It is worth noting that spending time in outdoor areas and in natural settings promotes restorative experiences such as relaxation and calmness (Kaplan, 1995), which may be translated into improved wellbeing. Going outdoors was set as the goal of each visit by the volunteer. A goal-oriented activity will lead to experiences of accomplishment. Accessing community amenities, such as recreational areas or shops, brings about situations that support the social role of the individual.

'Getting out of the house' is considered a key to active ageing (Rantanen et al., 2018). Well-designed infrastructure and availability of services promote going out (Rantakokko, Iwarsson, Portegijs, Viljanen, \& Rantanen, 2015) and thus support active ageing. For example, safe outdoor spaces and built environments and accessible transportation options are conducive to participation in meaningful life-situations. Build environments affect an individual's walking activity (Chapter in this book by Cerin, et al.), but older people with mobility limitations may need support from another individual simply to step out of the front door. A positive attitude to inclusion of older people in different life areas is also important. This entails purposeful activities such as being engaged in paid or voluntary work, having caring responsibilities, or smaller incidental activities such as helping or supporting neighbours. The social context of the 
activities may propel active ageing by providing social support but also through sense of responsibilities and social pressures.

Promotion of active ageing is a challenge for societies and individuals. The role of societies is to establish policies that provide the preconditions for active ageing that people can realize in their own lives. In the context of individual older people, active ageing becomes a reality when older people express what they wish to do and act toward their goals and when needed, other people provide support for this. 


\section{References.}

AARP. Retrieved from https://www.aarp.org/about-aarp/company/info-2016/history.html Active ageing index home. Retrieved from https://statswiki.unece.org/display/AAI Baker, P. S., Bodner, E. V., \& Allman, R. M. (2003). Measuring life-space mobility in community-dwelling older adults. Journal of the American Geriatrics Society, 51(11), 1610-1614. Baltes, P. B., \& Baltes, M. M. (1990). Psychological perspectives on successful aging: The model of selective optimization with compensation. In P. B. Baltes, \& M. M. Baltes (Eds.), Successful aging: Perspectives from the behavioral sciences (pp. 1-34). Cambridge: Cambridge University Press.

Bandura, A. (1977). Self-efficacy: toward a unifying theory of behavioural change. Psychol Rev, 84, 191-215.

Eronen, J., von Bonsdorff, M., Rantakokko, M., Portegijs, E., Viljanen, A., \& Rantanen, T. (2016). Socioeconomic status and life-space mobility in old age. Journal of Aging and Physical Activity, 24(4), 617-623.

Eronen, J., von Bonsdorff, M., Rantakokko, M., \& Rantanen, T. (2014). Environmental facilitators for outdoor walking and development of walking difficulty in community-dwelling older adults. Eur J Aging, 11, 67-75.

Frank, L.D., Andresen, M.A., \& Schmid, T.L. (2004). Obesity relationships with community design, physical activity, and time spent in cars. Am J Prev Med, 27, 87-96.

Freund, A.M., \& Riediger M. (2006). Goals as building blocks of personality and development in adulthood. In: Mroczek, D.K., \& Little T.D. (eds) Handbook of personality development (pp 353-372). Mahwah : Laurence Erlbaum Associates.

Havighurst, R.J. (1961). Successful aging. Gerontologist, 1, 8-13. 
Iwarsson, S., Horstmann, V., Carlsson, G., Oswald, F., \& Wahl, H. W. (2009). Person-environment fit predicts falls in older adults better than the consideration of environmental hazards only. Clinical Rehabilitation, 23(6), 558-567.

Kaplan, S. (1995). The restorative benefits of nature: toward an integrative framework. J Environ Psychol 15, 169-182.

Keskinen, K. E., Rantakokko, M., Suomi, K., Rantanen, T., \& Portegijs, E. (2018). Nature as a facilitator for physical activity: Defining relationships between the objective and perceived environment and physical activity among community-dwelling older people. Health \& Place, 49, 111-119.

Kulmala, J., Ngandu, T., Pajala, S., Lehtisalo, J., Levalahti, E., Antikainen, R., . . Kivipelto, M. (2016). Leisure-time and occupational physical activity in early and late adulthood in relation to later life physical functioning. Journal of Physical Activity \& Health, 13(10), 1079-1087.

Lawton, M. P., \& Nahemow, L. (1973). Ecology and aging process. In C. Eisdorfer, \& M. P. Lawton (Eds.), The psychology of adult development and aging (pp. 619-674). Washington DC: American Psychology Association.

Michie, S., van Stralen, M. M., \& West, R. (2011). The behaviour change wheel: A new method for characterising and designing behaviour change interventions. Implementation Science : IS, 6, 42-5908-6-42.

Poranen-Clark, T., von Bonsdorff, M. B., Rantakokko, M., Portegijs, E., Eronen, J., Kauppinen, M., ... Viljanen, A. (2018). Executive function and life-space mobility in old age. Aging Clinical and Experimental Research, 30(2), 145-151.

Poranen-Clark, T., von Bonsdorff, M. B., Rantakokko, M., Portegijs, E., Eronen, J., Pynnonen, K., ... Rantanen, T. (2018). The temporal association between executive function and life-space 
mobility in old age. The Journals of Gerontology.Series A, Biological Sciences and Medical Sciences, 73(6), 835-839.

Portegijs, E., Iwarsson, S., Rantakokko, M., Viljanen, A., \& Rantanen, T. (2014). Life-space mobility assessment in older people in finland; measurement properties in winter and spring. BMC Research Notes, 7(1), 323.

Portegijs, E., Keskinen, K. E., Tsai, L. T., Rantanen, T., \& Rantakokko, M. (2017). Physical limitations, walkability, perceived environmental facilitators and physical activity of older adults in finland. International Journal of Environmental Research and Public Health, 14(3), 10.3390/ijerph14030333.

Portegijs, E., Rantakokko, M., Edgren, J., Salpakoski, A., Heinonen, A., Arkela, M., . . Sipila, S. (2013). Effects of a rehabilitation program on perceived environmental barriers in older patients recovering from hip fracture: A randomized controlled trial. BioMed Research International, $2013,769645$.

Portegijs, E., Rantakokko, M., Mikkola, T. M., Viljanen, A., \& Rantanen, T. (2014). Association between physical performance and sense of autonomy in outdoor activities and life-space mobility in community-dwelling older people. Journal of the American Geriatrics Society, 62(4), 615-621.

Portegijs, E., Rantakokko, M., Viljanen, A., Rantanen, T., \& Iwarsson, S. (2017). Perceived and objective entrance-related environmental barriers and daily out-of-home mobility in communitydwelling older people. Arch Gerontol Geriatr, 69, 69-76.

Portegijs, E., Rantakokko, M., Viljanen, A., Rantanen, T., \& Iwarsson, S. (2017). Perceived and objective entrance-related environmental barriers and daily out-of-home mobility in communitydwelling older people. Archives of Gerontology and Geriatrics, 69, 69-76. 
Portegijs, E., Rantakokko, M., Viljanen, A., Sipila, S., \& Rantanen, T. (2016). Identification of older people at risk of ADL disability using the life-space assessment: A longitudinal cohort study. Journal of the American Medical Directors Association, 17(5), 410-414.

Portegijs, E., Tsai, L. T., Rantanen, T., \& Rantakokko, M. (2015). Moving through greater lifespace areas and objectively measured physical activity of older people. Plos One, (10), e0135308. Rantakokko, M., Iwarsson, S., Manty, M., Leinonen, R., \& Rantanen, T. (2012). Perceived barriers in the outdoor environment and development of walking difficulties in older people. Age and Ageing, 41(1), 118-121.

Rantakokko, M., Iwarsson, S., Portegijs, E., Viljanen, A., \& Rantanen, T. (2015). Associations between environmental characteristics and life-space mobility in community-dwelling older people. Journal of Aging and Health, 27(4), 606-621.

Rantakokko, M., Portegijs, E., Viljanen, A., Iwarsson, S., Kauppinen, M., \& Rantanen, T. (2016a). Changes in life-space mobility and quality of life among community-dwelling older people: A 2-year follow-up study. Quality of Life Research : An International Journal of Quality of Life Aspects of Treatment, Care and Rehabilitation, 25(5), 1189-1197.

Rantakokko, M., Portegijs, E., Viljanen, A., Iwarsson, S., Kauppinen, M., \& Rantanen, T. (2016b). Perceived environmental barriers to outdoor mobility and changes in sense of autonomy in participation outdoors among older people: A prospective two-year cohort study. Aging \& Mental Health, , 1-5.

Rantakokko, M., Portegijs, E., Viljanen, A., Iwarsson, S., \& Rantanen, T. (2013). Life-space mobility and quality of life in community-dwelling older people. Journal of the American Geriatrics Society, 61(10), 1830-1832. 
Rantakokko, M., Portegijs, E., Viljanen, A., Iwarsson, S., \& Rantanen, T. (2016). Mobility modification alleviates environmental influence on incident mobility difficulty among community-dwelling older people: A two-year follow-up study. PloS One, 11(4), e0154396. Rantakokko, M., Portegijs, E., Viljanen, A., Iwarsson, S., \& Rantanen, T. (2017). Task modifications in walking postpone decline in life-space mobility among community-dwelling older people: A 2-year follow-up study. The Journals of Gerontology.Series A, Biological Sciences and Medical Sciences, 72(9), 1252-1256.

Rantanen, T., Ayravainen, I., Eronen, J., Lyyra, T., Tormakangas, T., Vaarama, M., \& Rantakokko, M. (2015). The effect of an outdoor activities' intervention delivered by older volunteers on the quality of life of older people with severe mobility limitations: A randomized controlled trial. Aging Clinical and Experimental Research, 27(2), 161-169.

Rantanen, T., Portegijs, E., Kokko, K., Rantakokko, M., Tormakangas, T., \& Saajanaho, M. (2018). Developing an assessment method of active aging: University of jyvaskyla active aging scale. Journal of Aging and Health, , $898264317750449.10 .1177 / 0898264317750449$ [doi] Rantanen, T., Portegijs, E., Viljanen, A., Eronen, J., Saajanaho, M., Tsai, L. T., . . Rantakokko, M. (2012). Individual and environmental factors underlying life space of older people - study protocol and design of a cohort study on life-space mobility in old age (LISPE). BMC Public Health, 12, 1018.

Saajanaho, M., Rantakokko, M., Portegijs, E., Tormakangas, T., Eronen, J., Tsai, L. T., . . . Rantanen, T. (2015). Personal goals and changes in life-space mobility among older people. Preventive Medicine, 81, 163-167. 
Saajanaho, M., Rantakokko, M., Portegijs, E., Tormakangas, T., Eronen, J., Tsai, L. T., . . . Rantanen, T. (2016). Life resources and personal goals in old age. European Journal of Ageing, 13(3), 195-208.

Sakari, R., Era, P., Rantanen, T., Leskinen, E., Laukkanen, P., \& Heikkinen, E. (2010). Mobility performance and its sensory, psychomotor and musculoskeletal determinants from age 75 to age 80. Aging Clinical and Experimental Research, 22(1), 47-53.

Satariano, W. A., Guralnik, J. M., Jackson, R. J., Marottoli, R. A., Phelan, E. A., \& Prohaska, T. R. (2012). Mobility and aging: New directions for public health action. American Journal of Public Health, 102(8), 1508-1515.

Stenholm, S., Tiainen, K., Rantanen, T., Sainio, P., Heliovaara, M., Impivaara, O., \& Koskinen, S. (2012). Long-term determinants of muscle strength decline: Prospective evidence from the 22year mini-finland follow-up survey. Journal of the American Geriatrics Society, 60(1), 77-85. Tsai, L. T., Portegijs, E., Rantakokko, M., Viljanen, A., Saajanaho, M., Eronen, J., \& Rantanen, T. (2015). The association between objectively measured physical activity and life-space mobility among older people. Scandinavian Journal of Medicine \& Science in Sports, 25(4), e368-73.

Tsai, L. T., Rantakokko, M., Portegijs, E., Viljanen, A., Saajanaho, M., Eronen, J., \& Rantanen, T. (2013). Environmental mobility barriers and walking for errands among older people who live alone vs. with others. BMC Public Health, 13(1), 1054.

Tsai, L. T., Rantakokko, M., Rantanen, T., Viljanen, A., Kauppinen, M., \& Portegijs, E. (2016). Objectively measured physical activity and changes in life-space mobility among older people. The Journals of Gerontology.Series A, Biological Sciences and Medical Sciences, 71(11), 14661471. 
Tsai, L. T., Rantakokko, M., Viljanen, A., Saajanaho, M., Eronen, J., Rantanen, T., \& Portegijs, E. (2016). Associations between reasons to go outdoors and objectively-measured walking activity in various life-space areas among older people. Journal of Aging and Physical Activity, 24(1), 85-91.

Viljanen, A., Mikkola, T. M., Rantakokko, M., Portegijs, E., \& Rantanen, T. (2016). The association between transportation and life-space mobility in community-dwelling older people with or without walking difficulties. Journal of Aging and Health, 28(6), 1038-54.

von Bonsdorff, M. B., Rantanen, T., Sipila, S., Salonen, M. K., Kajantie, E., Osmond, C., . . . Eriksson, J. G. (2011). Birth size and childhood growth as determinants of physical functioning in older age: The helsinki birth cohort study. American Journal of Epidemiology, 174(12), 13361344.

World Health Organization. (2002a). Active ageing. A policy framework. geneva. Geneva: World Health Organization.

World Health Organization. (2002b). Towards a common language for functioning, disability and health ICF. Geneva: World Health Organization. 